\title{
BMJ Open Modern contraceptive use among HIV- infected women attending HIV care centres in Togo: a cross-sectional study
}

\author{
Issifou Yaya, ${ }^{1,2}$ Akouda Akessiwè Patassi, ${ }^{3}$ Dadja Essoya Landoh, ${ }^{4}$ \\ Essodjèlouna Manani Bignandi, ${ }^{5}$ Kanfitine Kolani, ${ }^{6}$ Abdel-Daim Daou Namoro, ${ }^{7}$ \\ P'Niwè Massoubayo Patchali, ${ }^{8}$ Lihanimpo Djalogue, ${ }^{9}$ Didier Koumavi Ekouevi, ${ }^{10,11}$ \\ Bayaki Saka $^{12}$
}

\begin{abstract}
To cite: Yaya I, Patassi AA, Landoh DE, et al. Modern contraceptive use among HIVinfected women attending HIV care centres in Togo: a crosssectional study. BMJ Open 2018;8:e019006. doi:10.1136/ bmjopen-2017-019006

- Prepublication history for this paper is available online. To view these files, please visit the journal online (http://dx.doi. org/10.1136/bmjopen-2017019006).
\end{abstract}

Received 11 August 2017 Revised 24 January 2018 Accepted 21 March 2018
Check for updates

For numbered affiliations see end of article.

Correspondence to Professor Bayaki Saka; barthelemysaka@yahoo.fr

\section{ABSTRACT}

Introduction Contraceptive use among HIV-infected women in Togo is poorly documented. We aim at assessing the prevalence of modern contraceptive use and associated factors among HIV-infected women in Togo. Design Cross-sectional study.

Setting The study was conducted in five HIV care centres in the Centrale and Kara regions in Togo.

Participants We included 461 HIV-positive women aged between 15 and 49 years and who were sexually active. Main outcome measure The outcome variable was HIVinfected women who were using modern contraceptive methods.

Results A total of $461 \mathrm{HIV}$-infected women were interviewed, with an average age of $34.3( \pm 7.1)$. Among them, 332 (73.1\%) women reported using contraceptive methods, mostly condom alone $(74.7 \%)$ or in combination with hormonal contraceptive (16.9\%). In multivariate analysis, education level (primary: adjusted OR $(\mathrm{aOR})=1.99,95 \% \mathrm{Cl}$ (1.05 to 3.76); secondary level and higher: $\mathrm{aOR}=3.95,95 \% \mathrm{Cl}(2.03$ to 7.67$))$, WHO clinical stage (stage II: aOR=0.7, $95 \% \mathrm{Cl}(0.37$ to 1.33$)$ ), follow-up in private care facilities ( $\mathrm{aOR}=2.54,95 \% \mathrm{Cl}(1.22$ to 5.29$)$ ) and having a child (aOR=2.51, $95 \% \mathrm{Cl}(1.41$ to 4.5$)$ ) were associated with higher contraceptive use, while marital status (living in union: $\mathrm{aOR}=0.45,95 \% \mathrm{Cl}(0.28$ to 0.74$)$ ) and WHO stages III and IV (aOR $=0.47,95 \% \mathrm{Cl}(0.24$ to 0.94)) were associated with lower contraceptive use. Conclusion About three-quarters of sexually active HIV-infected women in Togo were using contraceptive methods, and private health facilities favoured this contraceptive use. It is important to strengthen the implementation of interventions to increase the incentives for HIV-infected women to use contraception in Togo.

\section{BACKGROUND}

Although there has been a reduction in new infections of HIV of about $41 \%$ between 2000 and 2015, HIV infection continues to be a public health problem in Sub-Saharan Africa, where 25.6 million people lived with HIV. Women of reproductive age account for about two-thirds of them. ${ }^{1}$ The decline in the incidence of HIV infection is the effect

\section{Strengths and limitations of this study}

- The use of contraceptives such as condoms could provide dual protection against acquisition or transmission of sexually transmitted infections, including HIV.

- This study is one of the first studies in Togo focusing its interest on the contraceptive use among HIVpositive women.

- Education level, marital status, AIDS clinical stage, type of health centre and having children had influenced the use of contraceptive methods among HIVinfected women.

- It is suggested that caregivers should integrate family planning services in HIV care during follow-up visits.

- Finally, we relied on self-reported reproductive health behaviour through a face-to-face interview, which may introduce information bias.

of multiple interventions implemented to prevent HIV transmission among heterosexual and especially from mother-to-child HIV transmission. About 66000 children under 14 years were reported to be newly infected by HIV in Western and Central Africa at the end of $2015 .^{2}$ Most of these infections could have been prevented by antiretroviral therapy (ART) during pregnancy and more by contraceptive use among HIV-infected women, which is the fourth component of preventing mother-to-child transmission (PMTCT). In 2005, Reynolds et $a l^{3}$ estimated that the level of contraceptive use could prevent over 173000 unintended HIV-infected births each year in Sub-Saharan Africa.

Indeed, family planning showed numerous benefits for HIV-infected women, such as the reduction of morbidity and mortality due to pregnancy and also the improvement of health of HIV-infected women by reducing unintended pregnancies. Therefore family planning contributes to PMTCT of HIV. ${ }^{4}$ The 
use of contraceptives, mainly male and female condoms, could provide dual protection. It could protect against acquisition or transmission of sexually transmitted infections, including HIV. ${ }^{5}$ However, in Sub-Saharan Africa, given the progress in PMTCT with the expansion of ART, most of the HIV-infected women still have desire to have children, ${ }^{78}$ and the prevalence of contraceptive use varies according to the studies. In Western Africa, the use of contraceptive methods is not effective in HIV-infected women. ${ }^{9-11}$ In Ghana, a study showed that only $42.6 \%$ of HIV-infected women used modern contraceptive methods at Komfo Anokye Teaching Hospital in 2012, ${ }^{11}$ while in eastern Nigeria it was reported that $73.1 \%$ of HIV-infected women were using modern contraceptives in the same period. ${ }^{10}$ In many studies conducted in Sub-Saharan Africa, the reported factors influencing the use of contraceptive among HIV-positive women were sociodemographic characteristics (age, education, marital status), reproductive characteristics (desire to have children, number of children), being on ART and knowledge of the partner's HIV status. ${ }^{9-14}$

In 2015, Togo had about 110000 people living with HIV and AIDS (PLWHA), including 59000 women aged more than 15 years old and 9000 children aged $0-14$ years. ${ }^{15}$ In addition, the prevalence of HIV infection is almost twice higher among women than men (3.1\% vs $1.7 \%) .{ }^{16} \mathrm{HIV}$ prevalence among women attending antenatal consultation in Togo was $2 \%$ in $2015 .{ }^{17}$ In women of reproductive age, the prevalence of contraceptive use was estimated at $22 \%$ for all methods ( $16 \%$ for modern methods) in $2013-$ 2014. ${ }^{16}$ However, contraceptive use among HIV-infected women in Togo is poorly documented.

This study aims at assessing the prevalence of contraceptive use, as well as individual and structural factors that influenced the use of contraceptives among HIV-infected women enrolled in HIV care centres in two health regions in Togo.

\section{METHODS}

\section{Study design}

This was a cross-sectional study conducted in two health regions in Togo (Centrale and Kara regions) over a period of 4 months from May to August 2016. The study targeted HIV-positive women of reproductive age (15-49 years) and who were sexually active.

\section{Setting and study population}

Centrale and Kara regions are two of the six health regions in Togo located, respectively, about $350 \mathrm{~km}$ and $420 \mathrm{~km}$ from the capital Lomé. These two regions are characterised by important seasonal arrival of populations (from the other health regions, and sometimes from outside of the country (Togo)) during cultural and traditional events, increasing the risks of HIV transmission. In 2013, the prevalence of HIV infection was estimated at $2.2 \%$ in the Centrale region and $1.8 \%$ in the Kara region. ${ }^{16}$ There were 30 accredited medical centres in the two regions to provide healthcare to about 10361 PLWHA, including 616 children, enrolled and followed up in these centres. ${ }^{17}$

Women were eligible to participate in the study if they (1) were aged between 15 and 49 years old, (2) had a sexual partner within the last 6 months and (3) were enrolled in the selected centres for active ART.

\section{Sampling}

First, a random probability sampling proportional to the number of patients in the active file of the $30 \mathrm{HIV}$ care centres in the two regions was carried out to ensure representative centres with a high number of PLWHA. In a minimalist scenario, it is assumed that a sample of $15 \%$ of HIV care centres should be representative of all the centres. This led to the random selection of five HIV care centres for the implementation of this study. Then, a non-probabilistic, convenience sampling was carried out. Indeed, in these five selected HIV care centres, it was proposed to enrol any PLWHA who consulted for a follow-up from May to August 2016, who met the inclusion criteria and who consented to participate in the study. The prevalence of the use of at least one contraceptive method was assumed to be $50 \%$ with the precision of $5 \%$ and $20 \%$ refusal or incomplete data. Based on this assumption, the sample size was estimated at 461 HIV-infected women.

\section{Data collection}

Data collection was done using a standardised questionnaire in French, explained in the local language for participants if needed. The questionnaires were filled by the health workers. The questionnaire included sociodemographic information, clinical features, information on ART, sexual activity status, and knowledge on contraceptives and their use. Data on HIV status disclosure to the sexual partner were also collected among PLWHA. We defined modern contraception as the use of one of the following methods: sterilisation, condoms, contraceptive pill/oral contraceptives, intrauterine device, diaphragm, injection, emergency contraception or implant.

\section{Statistical analysis of data}

Data entry was performed using EpiData V.3.1 software. Data were then exported for statistical analyses using SPSS V.17.0.

For continuous variables, mean and SD were calculated, while for categorical variables we calculated the proportions. Our main outcome variable was HIV-infected women who were currently using any modern contraceptive methods. Pearson's $\chi^{2}$ test or Fisher's exact test was used when appropriate in bivariate analysis. Multivariate backwards stepwise logistic regression analysis was performed to identify independent risk factors for the dichotomous outcome contraceptive use or not. All variables significant during bivariate analysis at a $p$ value $<0.20$ were introduced in a logistic regression model to estimate the adjusted OR (aOR). Interactions between the independent variables were tested. All these analyses 
were performed with $95 \%$ CI. To verify the robustness of the results, a sensitivity analysis was conducted to confirm the results found. We have performed the analysis by including women who have never heard about contraceptive methods, and then we excluded them to appreciate the variability of the statistical associations. We did not observe significant variability and logically we excluded those women $(15 / 461)$ from the model. Our final model included only HIV-infected women who had heard about contraceptives methods.

\section{Ethical issues}

We obtained consent from patients who participated in the study. For each of the person surveyed, the objectives, benefits to participate in the survey and progress of the investigation were clearly stated, as well as their right to interrupt the interview without justification. An informed consent form signed after the verbal explanation was made by the investigating officer in the language understood by the participant.

\section{RESULTS}

\section{Sociodemographic and clinical characteristics}

Table 1 shows the sociodemographic and clinical characteristics of the participants. In total $461 \mathrm{HIV}$-infected women of reproductive age and who were sexually active were enrolled into this study, of whom 267 (57.9\%) were in the Centrale region and $194(42.1 \%)$ in the Kara region. The mean $( \pm \mathrm{SD})$ age of the participants was $34.3 \pm 7.1$ years, ranging from 16 to 49 years. Among them, $40.6 \%$ had primary education or higher education level (45.3\%), $54.7 \%$ were living in couple and $62.3 \%$ were living in an urban area. Out of the 461 women interviewed, $415(90.0 \%)$ were on ART and for more than 2 years for $71 \%$ of them. The mean $( \pm \mathrm{SD})$ duration on ART was $4.1 \pm 2.8$ years. A quarter $(25.4 \%)$ of the participants had a CD4 cell count of $<0.35 \times 10^{9} / \mathrm{L}$ at the last visit. Patients were classified as stage I $(55.0 \%)$ or stage II $(27.3 \%)$ based on the WHO clinical classification at the time of the survey. The partner's HIV status was unknown for $56.4 \%(260 / 461)$ of the participants. Most of the patients were followed up in a public hospital centre $(61.8 \%)$, in a centre with available doctor $(86.3 \%)$ or with a psychologist $(55.7 \%)$.

\section{Reproductive health outcome}

The majority of women $(85.3 \%)$ reported having at least one child, while six out of ten participants expressed desire of having kids. Four hundred and forty six (96.7\%) women reported that they heard about contraceptives methods. Among them, $70.2 \%$ (313/446) were informed by healthcare providers. At the time of the survey, the proportion of women who were using a contraceptive method was $74.7 \%(333 / 446)$ (table 1), and among them $74.5 \%$ (248/333) reported using condom, 8.4\% (28/333) were using hormonal contraceptive and $16.9 \%$ (56/333) reported using dual methods combining condom and hormonal contraceptive. For 15 (3.3\%) women who have never heard about contraceptives methods, we considered they had missing data for the variable contraceptive use.

Furthermore the proportion of women using contraceptive was significantly higher among participants with higher level of education, ranging from $57.1 \%$ in women with no education to $82.8 \%$ in those having reached the secondary education level or higher $(\mathrm{p}<0.001)$. However, this proportion was significantly higher $(\mathrm{p}<0.001)$ among women at stage I $(82.1 \%)$ than those at stage II $(70.0 \%)$ or those at stages III and IV $(58.4 \%)$. The prevalence of contraceptive use was significantly lower in women living in couple $(\mathrm{p}=0.002)$, higher among those who had children $(\mathrm{p}=0.032)$ and higher in women on ART for 2 years or more $(\mathrm{p}=0.025)$. Women followed up in a private centre $(\mathrm{p}<0.001)$ or a centre with a psychologist $(\mathrm{p}=0.011)$ were more susceptible to use contraceptive methods (table 1 ).

\section{Factors associated with contraceptive use}

In multivariate analysis, only five factors remained associated with contraceptive use: education level, marital status, clinical stage, type of health centre and having children. Women with primary education level or those with secondary education level or higher were, respectively, two times more likely $(\mathrm{aOR}=1.99,95 \% \mathrm{CI}(1.05$ to 3.76)) and four times more likely (aOR=3.95, 95\% CI (2.03 to 7.67)) to use a contraceptive method than those who did not have any education, whereas participants living in couple were $55 \%$ less likely $(\mathrm{aOR}=0.45,95 \%$ CI $(0.28$ to 0.74$))$ to use a contraceptive method. Women who reported having children and those followed up in a private structure were almost three times more likely (respectively, aOR=2.51, 95\% CI (1.41 to 4.5 ) and $\mathrm{aOR}=2.54,95 \% \mathrm{CI}(1.22$ to 5.29$))$ to report current use of contraceptive. Patients at AIDS clinical stage III or IV were $53 \%$ less likely $(\mathrm{aOR}=0.47,95 \%$ CI $(0.23$ to 0.87$))$ to use a contraceptive method than those at clinical stage I. In addition this likelihood of using contraceptive is even lower for HIV-infected women at AIDS clinical stage III or IV followed up in private centres $(\mathrm{aOR}=0.13,95 \% \mathrm{CI}$ (0.03 to 0.64$)$ ) (table 2$)$.

\section{DISCUSSION}

In this study, conducted in two regions in north of Togo, 96.7\% of HIV-infected women had heard about contraceptive methods and mainly from health providers. Education level, marital status, AIDS clinical stage, type of health centre and having children had influenced the use of contraceptive methods among HIV-infected women.

A high proportion of knowledge on contraceptive methods was also reported among women aged 15-49 years in the general population in Togo $(96.3 \%)$ in 2013-2014 ${ }^{16}$ and among HIV-infected women on ART in Ethiopia (97.0\%) in 2013. ${ }^{18}$ This showed that seropositive women were as exposed to reproductive health 
Open Access

Table 1 Characteristics of HIV-infected women in the study population $(n=461)$

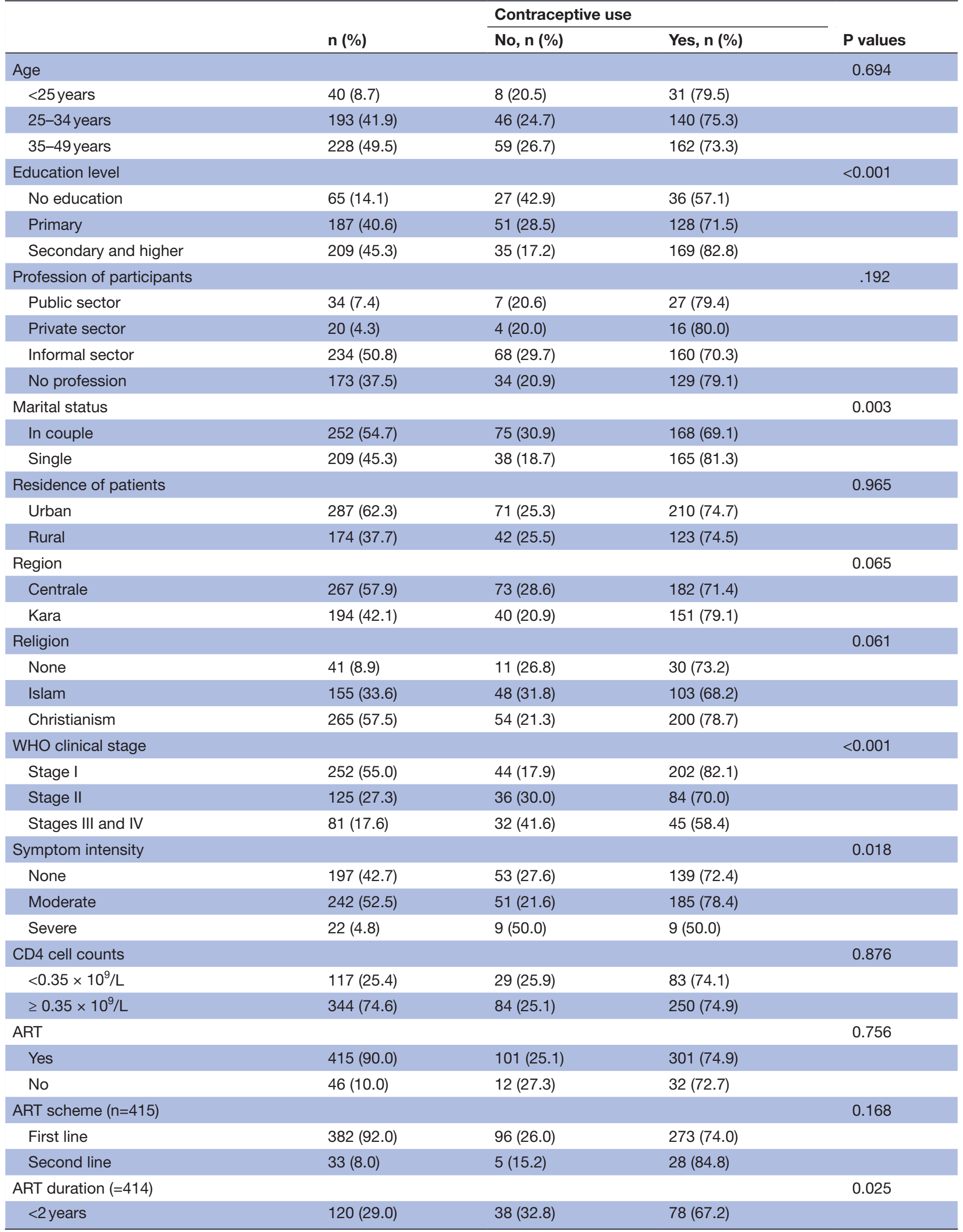

Continued 
Table 1 Continued

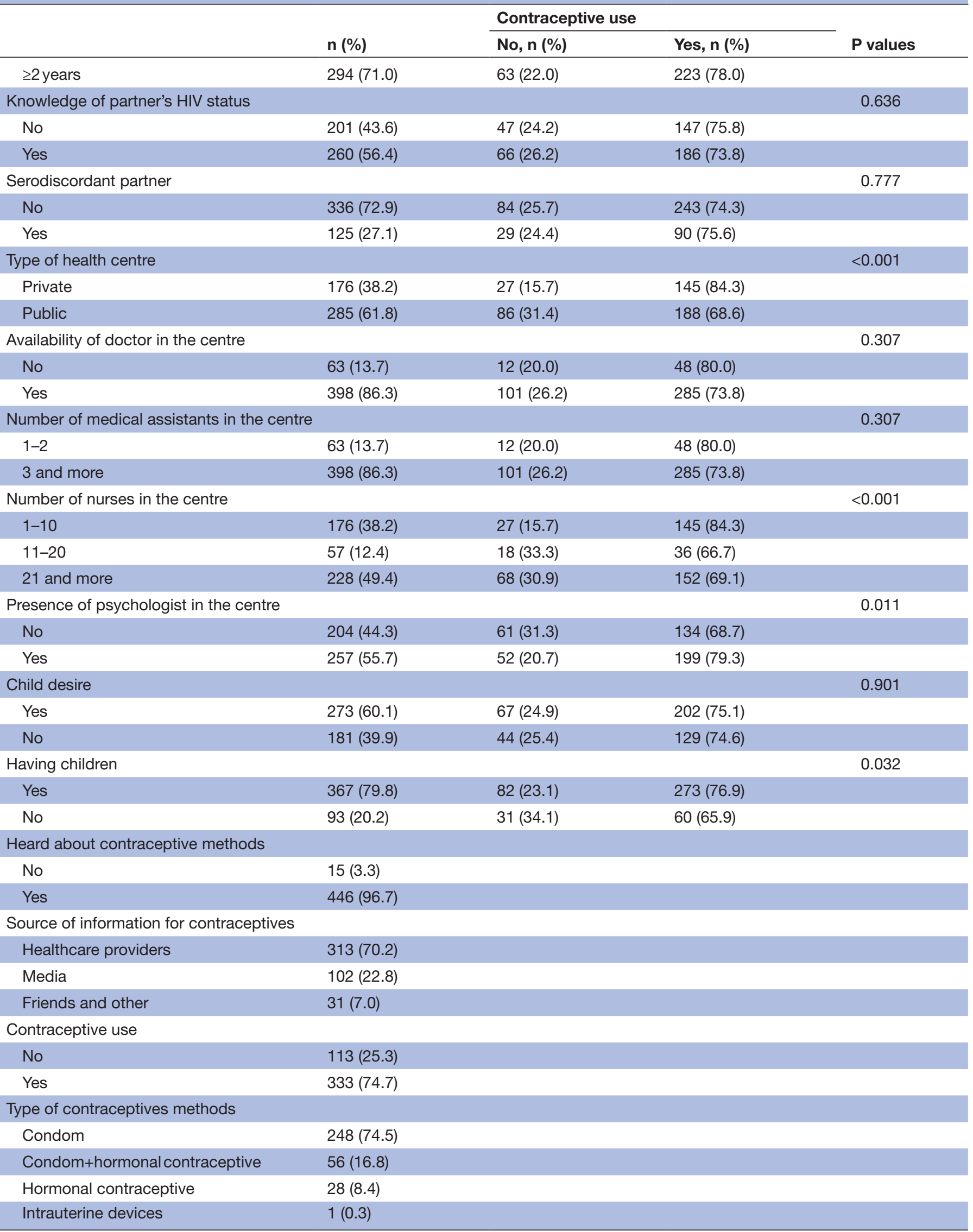

ART, antiretroviral therapy. 
Table 2 Factors associated with contraceptive use among $461 \mathrm{HIV}$-infected women in the Centrale and Kara regions in Togo

\begin{tabular}{|c|c|c|}
\hline & \multicolumn{2}{|c|}{ Logistic regression models } \\
\hline & $\begin{array}{l}\text { Univariate } \\
\text { OR }(95 \% \mathrm{Cl})\end{array}$ & $\begin{array}{l}\text { Multivariate } \\
\text { OR }(95 \% \mathrm{Cl})\end{array}$ \\
\hline Education level & $<0.001$ & $<0.001$ \\
\hline No education & 1 & 1 \\
\hline Primary & 1.88 (1.04 to 3.41$)$ & 1.99 (1.05 to 3.76$)$ \\
\hline Secondary and higher & 3.62 (1.95 to 6.72$)$ & 3.95 (2.03 to 7.67$)$ \\
\hline Profession & 0.192 & \\
\hline No profession & 1 & \\
\hline Public sector & 1.02 (0.41 to 2.53$)$ & \\
\hline Private sector & 1.05 (0.33 to 3.36$)$ & \\
\hline Informal sector & $0.62(0.39$ to 1.00$)$ & \\
\hline Marital status & 0.004 & 0.001 \\
\hline Single & 1 & 1 \\
\hline In couple & 0.52 (0.33 to 0.81$)$ & $0.45(0.28$ to 0.74$)$ \\
\hline Region & 0.066 & \\
\hline Centrale & 1 & \\
\hline Kara & 1.51 (0.97 to 2.36$)$ & \\
\hline Religion of participants & 0.063 & \\
\hline None & 1 & \\
\hline Islam & 0.79 (0.36 to 1.7$)$ & \\
\hline Christianism & 1.36 (0.64 to 2.89$)$ & \\
\hline WHO clinical stage & $<0.001$ & 0.101 \\
\hline Stage I & 1 & 1 \\
\hline Stage II & 0.51 (0.31 to 0.85$)$ & 0.7 (0.37 to 1.33 ) \\
\hline Stages III and IV & 0.31 (0.18 to 0.54$)$ & 0.47 (0.24 to 0.94$)$ \\
\hline ART scheme & 0.175 & \\
\hline First line & 0.51 (0.19 to 1.35$)$ & \\
\hline Second line & 1 & \\
\hline Type of health centre & $<0.001$ & 0.013 \\
\hline Public & 1 & 1 \\
\hline Private & 2.46 (1.52 to 3.98$)$ & 2.54 (1.22 to 5.29$)$ \\
\hline $\begin{array}{l}\text { Number of nurses in the } \\
\text { centre }\end{array}$ & 0.001 & \\
\hline $1-10$ & 1 & \\
\hline $11-20$ & 0.37 (0.19 to 0.75$)$ & \\
\hline 21 and more & 0.42 (0.25 to 0.69$)$ & \\
\hline $\begin{array}{l}\text { Presence of psychologist in } \\
\text { the centre }\end{array}$ & 0.011 & \\
\hline No & 1 & \\
\hline Yes & 1.74 (1.13 to 2.69$)$ & \\
\hline Having children & 0.033 & 0.004 \\
\hline No & 1 & 1 \\
\hline Yes & 1.72 (1.04 to 2.83$)$ & 2.51 (1.41 to 4.5 ) \\
\hline $\begin{array}{l}\text { WHO clinical stage*type of } \\
\text { health centre } †\end{array}$ & & 0.041 \\
\hline Stage I*public centre & & 1 \\
\hline Stage $\|^{*}$ private centre & & 0.54 (0.16 to 1.81$)$ \\
\hline $\begin{array}{l}\text { Stages III and IV }{ }^{*} \text { private } \\
\text { centre }\end{array}$ & & 0.13 (0.03 to 0.64$)$ \\
\hline
\end{tabular}

ART, antiretroviral therapy.

*WHO clinical stage.

†Type of health center. information as the rest of the general population, which is a major step towards the use of contraceptive methods.

We also found that almost three-quarters $(74.7 \%)$ of the participants were using a contraceptive method. This proportion was higher than that of $19.9 \%$ reported in the general population in 2013 in the Demographic and Health Surveys (DHS) in Togo. ${ }^{16}$ This was evidenced in prior studies conducted in Sub-Saharan Africa, ${ }^{12}{ }^{19}$ which reported that HIV-infected women seemed to be more likely to use contraceptives than HIV-negative women in public health facilities. This could be explained by the fact that HIV-infected women are frequently in contact with health workers and received more information on reproductive health during their follow-up. HIV-positive women are strongly encouraged to use contraceptive methods to prevent mother-to-child transmission of HIV. Similar results were found in South-East Nigeria $\left(73.1 \%^{10}\right)$ or in Ethiopia $\left(71.0 \%{ }^{20}\right)$, where a high proportion of HIV-infected women used contraceptives. However, lower rates of contraceptive use were reported among HIV-positive mothers in some previous studies in Ethiopia $\left(45.7 \%{ }^{18}\right)$, Uganda $\left(45 \%{ }^{14}\right)$ or Ghana $\left(42.6 \%{ }^{11}\right)$. These differences might be due to temporal and regional variabilities, including policy guidelines on reproductive health. In fact cultural characteristics and beliefs, including the perception of the value of a child in the community, may vary through African regions, and this could strongly influence the decision of using a contraceptive method or not. In addition, in Togo, healthcare providers in HIV clinics have recently benefited from a programme of strengthening their skills on family planning. Non-governmental organisations have also been established to promote reproductive health through the distribution of contraceptive methods. This would have encouraged HIV-infected women to use these methods.

As reported in previous studies in Western Africa, ${ }^{9-11}$ condom was the most common contraceptive method used by HIV-infected women in this study. Fearing possible pharmacokinetic interactions between hormonal contraceptive and antiretroviral in people living with $\mathrm{HIV}^{21}{ }^{22}$ healthcare providers more often advised HIV-infected women to avoid hormonal contraceptive method in favour of condoms. Condoms, in addition to being accessible and very effective in preventing unwanted pregnancies, contribute to the secondary prevention of HIV, especially in this context where more than four out of ten HIV-infected women did not know the HIV serostatus of their sexual partner. It is therefore important to know the influence of the HIV-infected woman in the decision-making process of condom use or not in a couple.

In this study, the decision to use contraceptive methods in HIV-infected women was influenced by several factors, including education level, marital status, AIDS clinical stage, type of health centre and having children.

Our findings revealed that women who attended school regardless of level (primary, secondary or higher education) were more likely to use contraceptives than those who could not read and write. Women education, which 
is key to societal development, remains a strong determinant of contraceptive use in Sub-Saharan African. This result was consistent with different studies conducted in Ethiopia ${ }^{23}{ }^{24}$ and in Malawi. ${ }^{25}$ Women who attended school were able to better analyse reproductive health information, and to understand the mechanisms of action, and the advantages and disadvantages of different contraceptive methods. This could reassure them about the use of these methods and allow them to make a judicious choice.

Our study showed that HIV-infected women who were living with a partner at the time of the survey were less likely to use contraceptive methods. In fact women in couple were more likely to express their desire to have children. This desire is increased by social pressure, which underlines a great importance of having children in the well-being of the couple. In addition, unmarried women would use contraceptive methods more than married women to avoid unwanted pregnancies, which could deteriorate their social image. Unlike our finding, Worke $e t a l^{24}$ in Ethiopia reported that married women were more likely to use contraceptives than those who were divorced or separated.

In our study, HIV-infected women followed up in private centres were more likely to use a contraceptive method. Although very few studies compared the quality of healthcare between the public and private sectors, particularly in family planning services delivery, it is generally evidenced that healthcare is better in private health centres. ${ }^{26}{ }^{27} \mathrm{In}$ private centres, even though they are non-profit-making facilities, it is reported that care providers are motivated to maximise patients' satisfaction in order to retain them, and this through the provision of good-quality healthcare. However, prior studies ${ }^{28} 29$ reported that public health facilities were more likely to offer family planning services. Therefore, it is important to improve the quality of family planning counselling and services delivery in public health facilities in order to encourage patients, including HIV-infected women, to use these services.

Among HIV-infected women, we found that the odds of contraceptive use were lowest at high AIDS clinical stage. Indeed patients at stages III and IV were less likely to use contraceptive methods. At these stages of the disease, patients were likely to suffer from opportunistic infections with certainly a reduction of sexual activities. This could impact on their demand for reproductive health services, including contraceptive use. Moreover, the odds of using contraceptives are even lower when women are followed up in a private centre. This could be explained by the fact that in our setting, HIV-infected patients in the advanced stage of the disease are most often referred for treatment in public hospitals.

HIV-infected women who had children, regardless of number, were more likely to use a contraceptive method. This result is consistent with prior studies conducted in Uganda ${ }^{30}$ Malawi ${ }^{25}$ and Ethiopia, ${ }^{23} 31$ which reported that contraceptive use increased with the number of children. In fact, among women who gave birth at least once, it is very common for them to use contraceptive methods to space or limit births, especially for those who have already reached the number of children they want.

\section{Limitations}

First, the sample may not be representative of the whole country because of cultural disparities across the country. Second, this study took place in health facilities with little chance of including patients who are less regular in the health centres and may have different characteristics. Sexually active women were defined as those engaging in sexual activity in the past 6 months; this definition used in the study could differ from other similar studies. In addition, we lacked information/analysis by contraceptive types, which can impact mother-to-child transmission. Finally, we relied on self-reported reproductive health behaviour through a face-to-face interview, which may introduce information bias. However, these biases would have had very negligible effects on the estimates in this study.

\section{CONCLUSION}

This study demonstrated a high prevalence of contraceptive use among HIV-infected women followed up in health facilities in Centrale and Kara regions in Togo. Private health facilities seemed to favour the use of contraceptive methods, but not in women at clinical stages III and IV. Despite these results, there is a need for an intensified effort to increase the reproductive health service utilisation particularly in public health facilities in these regions. HIV caregivers must also integrate family planning services in HIV care during follow-up visits.

\section{Author affiliations}

${ }^{1}$ Aix Marseille University, INSERM, IRD, SESSTIM, Sciences Economiques \& Sociales de la Santé \& Traitement de l'Information Médicale, Marseille, France

${ }^{2}$ ORS PACA, Observatoire Régional de la Santé Provence-Alpes-Côte d'Azur, Marseille, France

${ }^{3}$ Service de maladies infectieuses, CHU Sylvanus Olympio, Université de Lomé, Lomé, Togo

${ }^{4}$ World Health Organization, Country Office of Togo, Lomé, Togo

${ }^{5}$ Service de médecine générale, CHR Tomdè, Kara, Togo

${ }^{6}$ Service de gynécologie-obstétrique, Clinique Biasa, Lomé, Togo

${ }^{7}$ Gynécologie-obstétrique, Évaluation de programmes, Québec, Canada

${ }^{8}$ Division de la Santé Communautaire, Ministère de la Santé, Lomé, Togo

${ }^{9}$ Service de médecine interne, CHU, Kara, Togo

${ }^{10}$ Département de Sante Publique, Université de Lomé, Lomé, Togo

${ }^{11}$ Centre Africain de Recherche en Epidémiologie et en Santé Publique, Lomé, Togo

${ }^{12}$ Service de dermatologie, CHU Sylvanus Olympio, Lomé, Togo

Acknowledgements We would like to thank the health workers involved in data collection for their contribution. We acknowledge all patients who agreed to participate in this study.

Contributors IY was responsible for the conception of the study, participated in the study design, undertook the field study, conducted the data collection, analysis and interpretation, and wrote the manuscript. AAP and DEL were involved in data collection, analysis and interpretation. They wrote and finalised the manuscript. EMB, KK, A-DDN, PMP and LD were involved in data analysis and interpretation. They have revised and finalised the manuscript. DKE and BS were responsible for 
the overall scientific management of the study, for analysis and interpretation, and the preparation of the final manuscript. All the authors read and approved the final manuscript to be submitted for publication.

Funding This research received no specific grant from any funding agency in the public, commercial or not-for-profit sectors.

Disclaimer DEL works for the WHO, Togo Country Office. The authors are solely responsible for the views expressed in this manuscript and do not necessarily represent the decisions, policies or views of the WHO.

Competing interests None declared.

Patient consent Obtained.

Ethics approval This study was approved by the National AIDS and STI Programme of Togo (Ref Nº 098/2016/MS/DSSP/PNLS-IST).

Provenance and peer review Not commissioned; externally peer reviewed.

Data sharing statement All data from this study can be accessed and obtained through the corresponding author on request.

Open Access This is an Open Access article distributed in accordance with the Creative Commons Attribution Non Commercial (CC BY-NC 4.0) license, which permits others to distribute, remix, adapt, build upon this work non-commercially, and license their derivative works on different terms, provided the original work is properly cited and the use is non-commercial. See: http://creativecommons.org/ licenses/by-nc/4.0/

(c) Article author(s) (or their employer(s) unless otherwise stated in the text of the article) 2018. All rights reserved. No commercial use is permitted unless otherwise expressly granted.

\section{REFERENCES}

1. World Health Oraganiation. HIVIAIDS. Geneva, 2016.

2. UNAIDS. AIDS by the numbers. Geneva, 2016.

3. Reynolds HW, Janowitz B, Wilcher R, et al. Contraception to prevent HIV-positive births: current contribution and potential cost savings in PEPFAR countries. Sex Transm Infect 2008;84(Suppl 2):ii49-ii53.

4. Crankshaw TL, Smit JA, Beksinska ME. Placing contraception at the centre of the HIV prevention agenda. Afr J AIDS Res 2016;15:157-62.

5. Holmes KK, Levine R, Weaver M. Effectiveness of condoms in preventing sexually transmitted infections. Bull World Health Organ 2004;82:454-61.

6. WHO, USAID, FHI. Strategic considerations for strengthening the linkages between family planning and HIVIAIDS policies, programs, and services. Geneva, 2009.

7. Wilcher R, Cates W. Reproductive choices for women with HIV. Bull World Health Organ 2009;87:833-9.

8. Maier M, Andia I, Emenyonu N, et al. Antiretroviral therapy is associated with increased fertility desire, but not pregnancy or live birth, among HIV+ women in an early HIV treatment program in rural Uganda. AIDS Behav 2009;13(Suppl 1):28-37.

9. Ogbe AE, Mutihir JT. Pattern of contraception among HIV positive women in Jos University Teaching Hospital. Niger J Med 2012;21:11-15.

10. Ezugwu EC, Nkwo PO, Agu PU, et al. Contraceptive use among HIVpositive women in Enugu, southeast Nigeria. Int J Gynaecol Obstet 2014;126:14-17.

11. Laryea DO, Amoako YA, Spangenberg K, et al. Contraceptive use and unmet need for family planning among HIV positive women on antiretroviral therapy in Kumasi, Ghana. BMC Womens Health 2014;14:126

12. Kimani J, Warren $\mathrm{C}$, Abuya $\mathrm{T}$, et al. Family planning use and fertility desires among women living with HIV in Kenya. BMC Public Health 2015;15:909.

13. Lawani LO, Onyebuchi AK, lyoke CA. Dual method use for protection of pregnancy and disease prevention among HIV-infected women in South East Nigeria. BMC Womens Health 2014;14:39.

14. Nieves Cl, Kaida A, Seage GR, et al. The influence of partnership on contraceptive use among HIV-infected women accessing antiretroviral therapy in rural Uganda. Contraception 2015;92:152-9.

15. ONUSIDA Togo. Estimations VIH et SIDA 2015. Lome, 2015.

16. Ministère de la Planification du Développement et de l'Aménagement du Territoire (MPDAT), Ministère de la Santé (MS), ICF International. Enquête Démographique et de Santé au Togo 2013 - 2014. Rockville, Maryland, USA, 2015.

17. Programme National de Lutte contre le Sida et le IST au Togo PNLSIST. Rapport annuel d'activités. PNLS - Togo: Lomé, 2015.

18. Abeje G, Motbaynor A. Demand for family planning among HIV positive women on ART: the case of South Gondar and North Wollo Zones Amhara region. BMC Res Notes 2016;9:43.

19. Bankole A, Biddlecom AE, Dzekedzeke K. Women's and men's fertility preferences and contraceptive behaviors by HIV status in 10 sub-Saharan African countries. AIDS Educ Prev 2011;23:313-28.

20. Asfaw HM, Gashe FE. Contraceptive use and method preference among HIV positive women in Addis Ababa, Ethiopia: a cross sectional survey. BMC Public Health 2014;14:566.

21. Mildvan D, Yarrish R, Marshak A, et al. Pharmacokinetic interaction between nevirapine and ethinyl estradiol/norethindrone when administered concurrently to HIV-infected women. J Acquir Immune Defic Syndr 2002;29:471-7.

22. Carten ML, Kiser JJ, Kwara A, et al. Pharmacokinetic interactions between the hormonal emergency contraception, levonorgestrel (Plan B), and Efavirenz. Infect Dis Obstet Gynecol 2012;2012:1-4.

23. Melaku YA, Zeleke EG. Contraceptive utilization and associated factors among HIV positive women on chronic follow up care in Tigray Region, Northern Ethiopia: a cross sectional study. PLoS One 2014;9:e94682.

24. Worke MD, Bezabih LM, Woldetasdik MA. Utilization of contraception among sexually active HIV positive women attending art clinic in University of Gondar Hospital: a hospital based cross-sectional study. BMC Womens Health 2016;16:67.

25. Habte D, Namasasu J. Family planning use among women living with HIV: knowing HIV positive status helps - results from a national survey. Reprod Health 2015;12:41.

26. Agha S, Do M. The quality of family planning services and client satisfaction in the public and private sectors in Kenya. Int J Qual Health Care 2009;21:87-96.

27. Hutchinson PL, Do M, Agha S. Measuring client satisfaction and the quality of family planning services: a comparative analysis of public and private health facilities in Tanzania, Kenya and Ghana. BMC Health Serv Res 2011;11:203.

28. Kakoko DC, Ketting E, Kamazima SR, et al. Provision of family planning services in Tanzania: a comparative analysis of public and private facilities. Afr J Reprod Health 2012;16:140-8.

29. Barden-O'Fallon J. Availability of family planning services and quality of counseling by faith-based organizations: a three country comparative analysis. Reprod Health 2017;14:57.

30. Muyindike W, Fatch R, Steinfield R, et al. Contraceptive use and associated factors among women enrolling into HIV care in southwestern Uganda. Infect Dis Obstet Gynecol 2012;2012:1-9.

31. Polisi A, Gebrehanna E, Tesfaye G, et al. Modern contraceptive utilization among female ART attendees in health facilities of Gimbie town, West Ethiopia. Reprod Health 2014;11:30. 